\title{
Bicycle frame from hemp fibre filament wound composites
}

A. Chaikittiratana ${ }^{1)}$, K. Suwanpakpraek ${ }^{1}$, S. Pornpeerakeat ${ }^{1}$, S. Limrungruengrat ${ }^{1}$, J. Dietz-Röthlingshöfer ${ }^{2)}$

1) Department of Mechanical and Aerospace Engineering, arisara.c@eng.kmutnb.ac.th, k.suwanpakpraek@gmail.com, sacharuck.p@fte.kmuntb.ac.th, me.sitthichai@gmail.com, King Mongkut's University of Technology North Bangkok, Bangsue, Bangkok 10800, Thailand

2) Faculty of Mechanical Engineering, joshua.dietz-roethlingshoefer@s2012.tu-chemnitz.de, Chemnitz University of Technology, 09126 Chemnitz, Germany

\section{Keywords}

Bicycle Frame, Composites, Filament Winding, Finite Element Methods, Hemp Fibre

\begin{abstract}
This work presents an initial study for hemp fibre produced in Thailand. The study focuses on the application of the filament winding technique in the production of hemp-epoxy composite tubes for a bicycle frame. The motivation is to produce hemp fibre composites from locally available resources in Thailand. For the initial trail, existing bicycle steel tubes were replaced by $\pm 45^{\circ}$ filament wound hempepoxy composites with thin aluminium inner layers. The mechanical properties of the hemp-epoxy composites were studied according to the ASTM standard. Two static load cases were chosen and considered for a $100 \mathrm{~kg}$ cyclist sitting on the saddle and pedalling while standing. The internal forces and moments were calculated for the frame and frame tubes. The stress and buckling analyses were performed using the finite element method for frame tubes considering the above loading cases. The finite element analysis shows that hemp-epoxy composite tubes with $\pm 45^{\circ}$ fibre orientation can be used as bicycle frame tubes and meet the design specifications under the considered static load conditions. The filament winding process was accomplished successfully at KMUTNB using an automated desktop filament winding machine.
\end{abstract}

\section{Introduction and background}

For over a thousand years, humankind has been using hemp bast fibres for the production of textiles and ropes. Hemp fibre offers an acceptable specific strength and modulus. Despite disadvantages such as high moisture absorption, hydrophilic surface and variability of properties, hemp fibre still has many advantages over synthetic fibres, e.g. glass, carbon or aramid fibres, which include a lower carbon footprint, lower production energy, sustainable availability, less abrasiveness, good thermal, acoustic insulation and damping properties [1-3]. Recently, hemp fibre has received increasing attention and has been shown to be an adequate reinforcements replacing synthetic fibres in lightweight composite applications such as sporting goods, automotive components, musical instruments, furniture and interiors [4-5]. One of the outstanding applications of hemp fibre is the "hemp bike" by Mobitecture Advanced Design [6], which has demonstrated the potential of natural fibres as an alternative to synthetic fibres in load-bearing structures.

In Thailand, hemp is grown and cultivated mainly by hill tribe people in the north known as "Hmong". Hemp fibre is produced by a traditional manual process and used mostly for clothing and other household goods. This study explores the possibility of an alternative utilisation of Thai Hmong hemp fibre as long fibre reinforcement in structural composites. A preliminary study on the production of composite tubes from Thai hemp fibre using filament winding process was carried out. The mechanical 
properties of hemp-epoxy composites and the possibility of employing hemp composite tubes for structural applications such as bicycle frame tubes were investigated and are presented in the following sections.

\section{Experimental work}

\subsection{Hemp fibre and matrix}

The hemp fibres in this study were used in the form of yarns, as shown in Figure 1a. It was produced by Thai Hmong people in the Tak province using the traditional method which involved manually stripping long hemp strands from the stems, pounding them with stones, connecting the strands to long fibres by twisting and spinning them into long yarns, boiling the yarns in water mixed with ashes and winding them up. The hemp yarn measured approximately $2 \mathrm{~mm}$ in width and $0.5 \mathrm{~mm}$ in thickness. The measured density was $1.265 \pm 0.05 \mathrm{~g} / \mathrm{cm}^{3}$. The matrix system used was the epoxy resin Epotec YD 582 and the hardener Epotec TH7257 manufactured by Aditya Birla Chemicals (Thailand) Ltd. The mixing ratio used was $2: 1$ by weight.

\subsection{Hemp composite fabrication by filament winding}

In a previous study [7], hemp-epoxy composite tubes were produced by manual filament winding, which is a highly labour intensive method. In this study, a commercially available automated desktop filament winder, $\mathrm{X}$ winder model $4 \mathrm{X}-23$, was used in order to increase the speed, control and repeatability of the winding process for the composite production. The machine has four axes of motion: a rotating spindle axis, two linear carriage axes, and a rotating axis for the winding head. It is controlled by a computer via the X-winder 2.0 software.

\subsubsection{Unidirectional reinforced composites}

Unidirectional composite laminates were prepared for the investigation of the mechanical tensile properties of unidirectional composite laminates. Hemp fibres were impregnated in a resin bath and in one direction wound by the aforementioned automated winding machine on a $250 \mathrm{~mm} \times 300 \mathrm{~mm} \times 20$ $\mathrm{mm}$ wooden frame shown in Figure $1 \mathrm{~b}$. Additional resin was manually added to the laminates after the winding process to ensure complete wetting of the fibre and subsequently allowed to cure at room temperature for 24 hours. The unidirectional samples of the $2 \mathrm{~mm}$ thick laminates were cut into strips (Figure 1c) in accordance with ASTM D3039/D3039M. The composite samples produced were found to have density of $1.13 \pm 0.019 \mathrm{~g} / \mathrm{cm}^{3}$ and a fibre volume fraction of approximately $30 \%$. To study the composite properties in the main material directions, the samples were cut using mechanical saw with a fibre orientation inclined at $0^{\circ}, 45^{\circ}$ and $90^{\circ}$ to the load direction and glass fibre composite tabs were bonded at sample ends with epoxy adhesive.
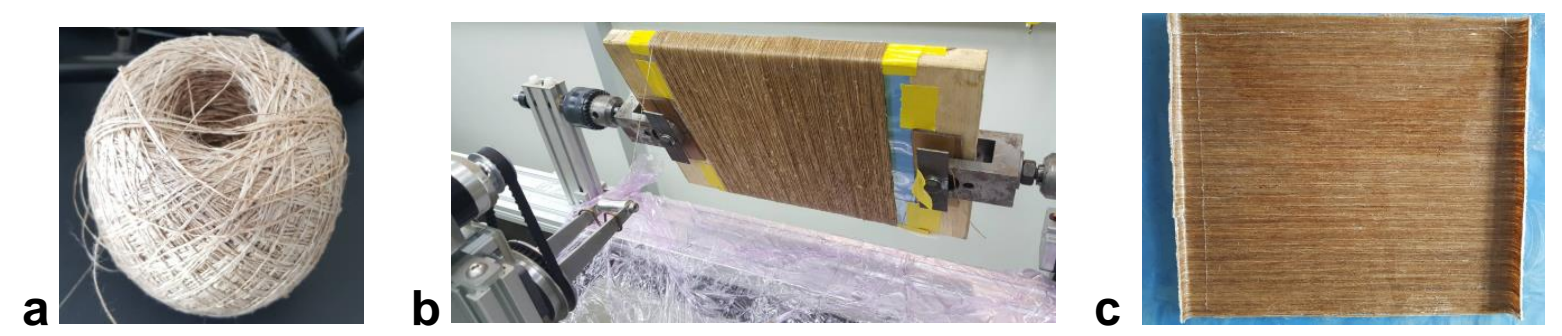

Figure 1: (a) Hemp fibre used in this study produced by the Thai Hmong hill tribe. (b) Unidirectional alligning of the fibres by the automated filament winding process. (c) Unidirectional hemp composite laminate.

\subsubsection{Composite tubes}

The possibility of fabricating hemp-epoxy composite bicycle frame tubes from hemp fibre produced by Thai Hmong people using the automated filament winding technique was investigated. The composite tubes were produced by winding resin impregnated hemp yarns over thin-walled aluminium tubular 
cores of $1 \mathrm{~mm}$ wall thickness. The fibre volume fraction of hemp composite was the same as in 2.2.1. Two different diameters of aluminium tubular cores were used $(25.4 \mathrm{~mm}$ and $19 \mathrm{~mm})$. In the current study hemp yarn was wound with a winding angle of $45^{\circ}$, which resulted in a fibre orientation of $\pm 45^{\circ}$. Stacking sequences $\left[{ }^{4} 45^{\circ}\right]_{2}$ were constructed for each composite tube. After the automated winding, additional resin was manually applied to the laminated tube to ensure the complete wetting and minimise air bubbles. The composite tube was left on the prepared stand, which rotated continuously throughout the gelling of the resin. The curing process was achieved at room temperature for 24 hours. In the following section it is shown that for the application of bicycle frame tubes it is better to use tubes constructed as hybrid hemp-epoxy composite/aluminium structures. Thus, the tubular aluminium cores employed as mandrels were kept and used as aluminium inner layers. The additional process of removing the aluminium mandrel was eliminated. The fabricated tubes with thin-walled aluminium inner cores were assembled into a bicycle frame at the existing steel joints as shown in Figure $2 \mathrm{~b}$. The fabricated composite tubes have finalised outside diameters of $27.7 \pm 0.3 \mathrm{~mm}, 30.9 \pm 0.3,32.0 \pm 0.2$ for the top tube, seat tube and bottom tube respectively.

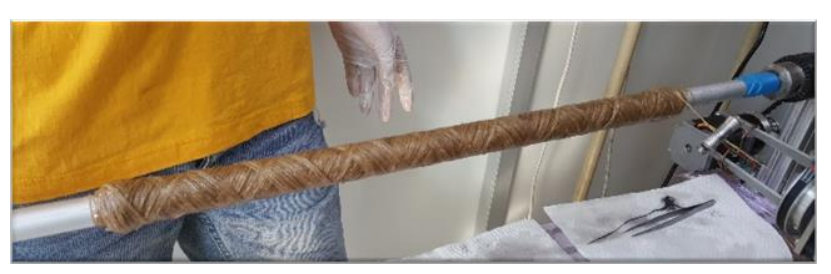

a

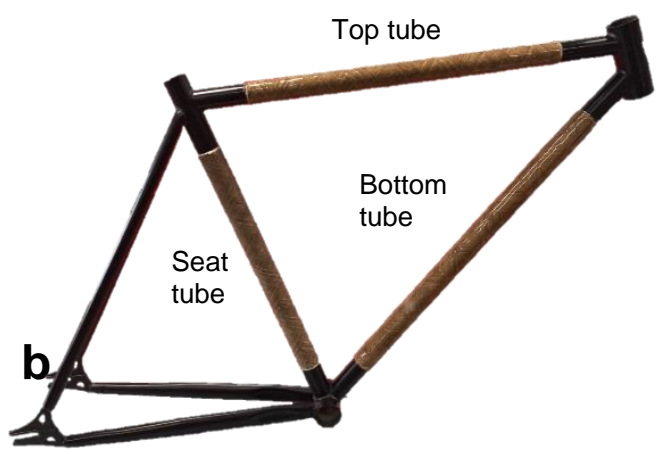

Figure 2: (a) Filament winding process for producing hemp-epoxy composite tubes. (b) Bicycle frame made from filament wound hemp-epoxy composite tubes produced in this work.

\subsection{Mechanical testing and properties}

The tensile tests were performed on an Instron testing machine model 5567 with a $30 \mathrm{kN}$ load cell. The crosshead speed used was $2 \mathrm{~mm} / \mathrm{min}$. Strain was measured with a clip-on extensometer with a gauge length of $25 \mathrm{~mm}$. Figure 3 illustrates the setup for tensile testing. The corresponding stress-strain diagrams for samples with different fibre orientations to the load axis are presented in Figure 4a. The samples after the tensile tests are shown in Figure 4b. Assuming an orthotropic and a plane stress state, the elastic properties in the main material directions can be estimated from the following relationship [8].

$$
E_{\theta}=\frac{1}{\frac{1}{E_{1}} \cos ^{4} \theta+\frac{1}{E_{2}} \sin ^{4} \theta+\left[\frac{1}{G_{12}}-\frac{2 v_{12}}{E_{1}}\right] \cos ^{2} \theta \sin ^{2} \theta}
$$

$E_{\theta}$ is the off-axis Young's modulus, $\theta$ is the angle of fibre orientation with respect to the load axis. The subscripts 1 and 2 are axes of composite materials. In the work by Madsen [9], the Poisson's ratio $v_{12}$ was as assumed to be 0.1 lower than $v_{m}$, the matrix Poisson's ratio for natural fibre epoxy composites, adopting the results shown by Cichocki and Thomason [10]. Thus, in this study $v_{12}$ was assumed as 0.27 . The strength values of composites in material coordinates can be estimated from [11]

$$
S_{1}=S_{\theta} \cos ^{2} \theta\left(\text { at } \theta=0^{0}\right), \quad S_{2}=S_{\theta} \sin ^{2} \theta\left(\text { at } \theta=90^{\circ}\right), \quad S_{12}=\frac{1}{2} S_{\theta} \sin 2 \theta\left(\text { at } \theta=45^{0}\right)
$$

$S_{1}, S_{2}$ and $S_{12}$ are the tensile strength values and shear strength in the material axes (1,2). The 1-axis lies along the fibre direction. $S_{\theta}$ is the tensile strength of the composite with fibre orientation angle $\theta$. The elastic properties and the strength in materials axes are listed in Table 1. 
It can be expected that the strength $S_{1}$ in compression is lower than $S_{1}$ in tension. It was shown in the work of Węcławski et.al. [12] that the compressive strength $S_{1}$ was about $60 \%$ of the strength value $S_{1}$ under tension for hemp fibre wound composites and therefore this approximation is adopted in this work.
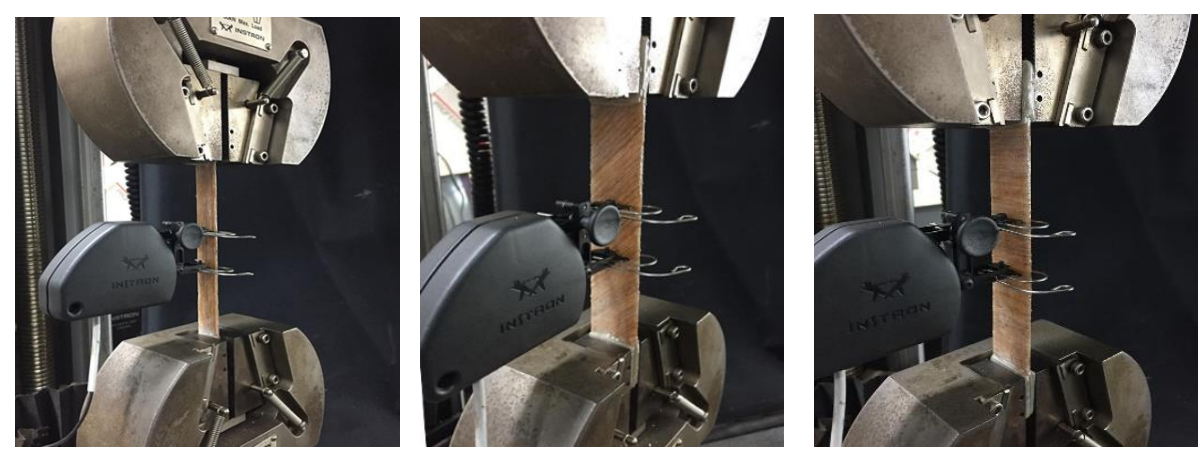

Figure 3: Experiment set-up for tensile testing of filament-wound test samples with $0^{\circ}, 45^{\circ}$ and $90^{\circ}$ fibre orientations to the load axis respectively (from left to right).
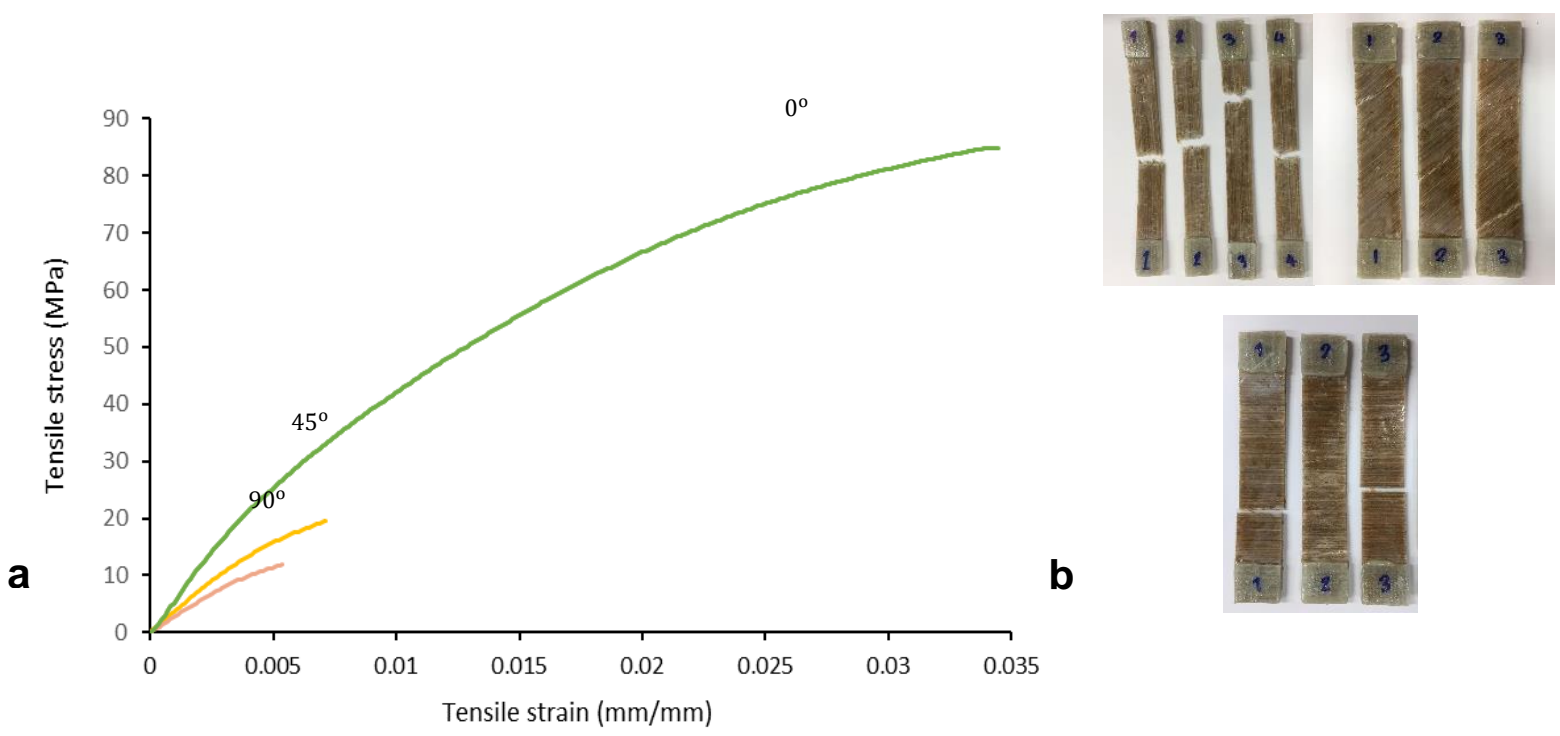

Figure 4: (a) The stress-strain plots obtained from the tensile tests at various fibre orientations.

(b) Unidirectional samples with fractures after the testing.

Table 1 Mechanical properties of hemp-epoxy composite determined from experimental study

\begin{tabular}{ccccccc}
\hline & \multicolumn{3}{c}{ Elastic properties (GPa) } & \multicolumn{4}{c}{ Strength (MPa) } \\
\hline $\boldsymbol{E}_{\boldsymbol{1}}$ & $\boldsymbol{E}_{\mathbf{2}}$ & $\boldsymbol{G}_{\mathbf{1 2}}$ & $\boldsymbol{V}_{\mathbf{1 2}}$ & $\boldsymbol{S}_{\boldsymbol{1}}$ & $\boldsymbol{S}_{\boldsymbol{2}}$ & $\boldsymbol{S}_{\mathbf{1 2}}$ \\
\hline $6.28 \pm 0.3$ & $2.90 \pm 0.3$ & $1.33 \pm 0.1$ & $0.27^{*}$ & $81.14 \pm 3.8$ & $11.91 \pm 0.4$ & $8.95 \pm 1.2$ \\
\hline
\end{tabular}

*Approximated value

\section{Finite element analysis of hemp bicycle tubes}

\subsection{Structural analysis of the bicycle frame to determine equivalent loads}

The dimensions of the existing bicycle frame studied in this work are shown in Figure 5 . The frame consists of 3 main tubular elements, namely top tube, bottom tube and seat tube. The existing main tubes were made of steel and replaced by hemp-epoxy composites. In order to determine the equivalent loads acting on these 3 main tubular elements, the structural analysis of the frame was performed using 
the finite element software SAP2000 (Computers and Structures, Inc., USA.) for 2 separate static, inplane vertical load cases: 1) $100 \mathrm{~kg}$ on the saddle (sitting) and 2) $100 \mathrm{~kg}$ on the centre of bottom bracket (standing pedalling), based on Refs [13,14]. The frame was initially represented as a simplified 3D rigidjointed steel frame and beam elements were used for structural modelling. The load and boundary conditions are depicted in Figure 6 . The head tube is free to move horizontally in $x$-direction, while the rear dropouts are assumed to be pin-supported (fixed in position but free to rotate). The equivalent loads (axial forces, shear forces and moments) on the three main tubes obtained from the analysis are listed in Table 1 for the 2 load cases considered. Subsequently, the equivalent loads were used in the stress analysis described in the following section. The substituting composite tubes should be able to withstand these equivalent loads without failures.

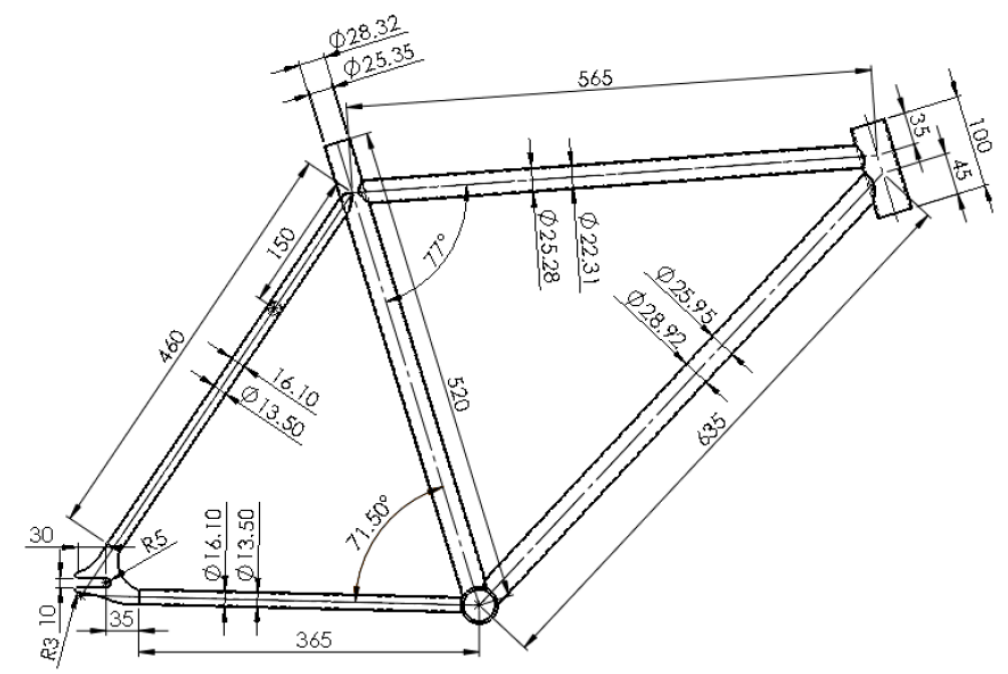

Figure 5: Dimensions and geometries of the bicycle frame analysed.

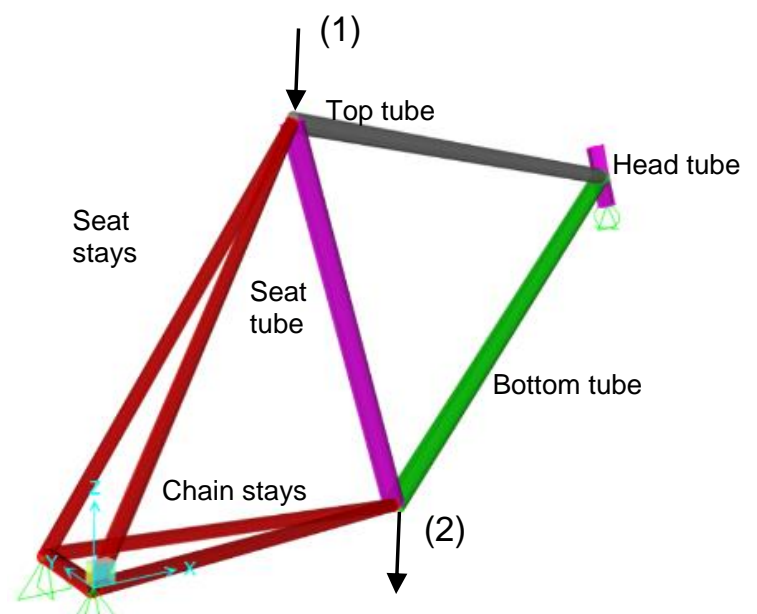

Figure 6: The structural model used for the analysis of the equivalent loads on main tube structures with boundary conditions and load position for load case (1) and (2). 
Table 2 Equivalent loads in main tubular structures

\begin{tabular}{cccc}
\hline \multirow{2}{*}{ Member } & Equivalent load & \multicolumn{2}{c}{ Load case } \\
\cline { 3 - 4 } & & $\begin{array}{c}\text { (1) } 100 \mathrm{kgf} \text { on } \\
\text { saddle }\end{array}$ & $\begin{array}{c}\text { (2) } 100 \mathrm{kgf} \text { at bottom } \\
\text { bracket }\end{array}$ \\
\hline \multirow{2}{*}{ Top tube } & Axial force $(\mathrm{N})$ & -285.23 & -462.75 \\
& Shear force $(\mathrm{N})$ & 6.71 & 9.87 \\
& Moment $(\mathrm{Nm})$ & -0.76 & -1.3 \\
\hline \multirow{2}{*}{ Bottom tube } & Axial force $(\mathrm{N})$ & 404.25 & 658.58 \\
& Shear force $(\mathrm{N})$ & 8.06 & 10.51 \\
& Moment $(\mathrm{Nm})$ & -1.04 & -1.26 \\
\hline \multirow{2}{*}{ Seat tube } & Axial force $(\mathrm{N})$ & -294.2 & 547.35 \\
& Shear force $(\mathrm{N})$ & -2.38 & -3.77 \\
& Moment $(\mathrm{Nm})$ & 0.63 & 0.97 \\
\hline
\end{tabular}

Note: Axial force is positive in tension. Shear force and Moment are to the left end of the element, positive when clockwise rotation is caused at the left end.

\subsection{Stress and buckling load analyses}

Two possibilities of material substitutions for steel tubes were considered: tubes made from hemp fibreepoxy wound composite and hemp fibre-epoxy wound composite/aluminium. In the latter case, thinwalled aluminium tubular cores are used as the inner layer of for the tubular structures. The replacing tubes are to be assembled on the existing steel joints. The stress analysis for the main tubes corresponding to the moments and shear loads listed in Table 2 was performed using a finite element package ABAQUS (Simulia, Dassault Systèmes, France) for the two replacement alternatives. The C3D8 Linear Brick solid elements were used in the finite element model. Over 80,000 elements were used in the modelling of each tube. The 1,2 and 3 axes, the main material axes of each ply, were assigned in the FE model in relation to the reference coordinate system $(x, y, z)$ as shown in Figure $6 a$. The mechanical properties of the hemp-epoxy composite used are listed in Table 2. The additional properties of the composite required by the FE programme were determined from experimental data from a previous, unpublished study as follows: $E_{3}=E_{2,} v_{13}=v_{12}$ and $v_{23}=0.37$ which corresponds to the Poisson's ratio of epoxy. $G_{13}=G_{12}$ and $G_{23}=0.98 \mathrm{GPa}$, which corresponds to the shear modulus of epoxy. The assumption of linear elasticity of the material was applied to the composites and aluminium. The elastic properties of the aluminium used were $E=70 \mathrm{GPa}, G=26.92 \mathrm{GPa}, v=0.3$ [7]. The maximum stresses in the composite material coordinates $\sigma_{1}, \sigma_{2}$, and $\tau_{12}$ are shown in Table 3 . Applying the maximum stress failure theory, the safety factor values (S.F.) are reported in brackets in Table 3 .

a

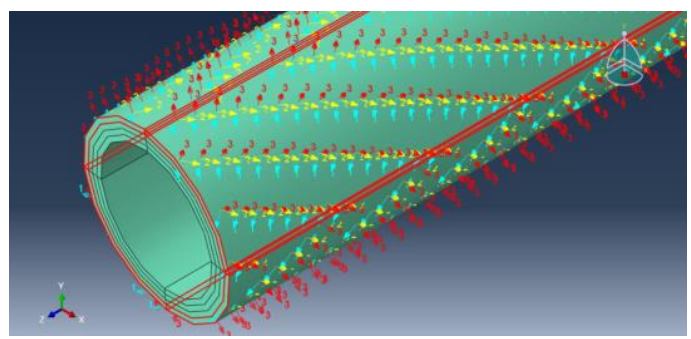

b

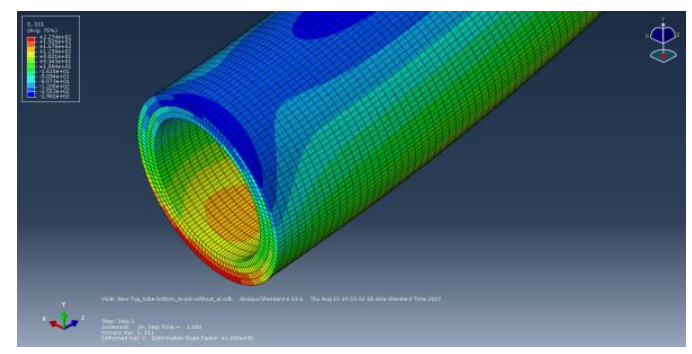

Figure 6: (a) Directions of material axes assigned in FE model. (b) Example of stress $\sigma_{1}$ contour in the composite layers 
Table 3 Maximum stresses in material axes in main tubular elements and buckling loads

\begin{tabular}{|c|c|c|c|c|}
\hline \multirow[t]{2}{*}{ Member } & \multirow{2}{*}{$\begin{array}{c}\text { Max stress } \\
\text { (in composite } \\
\text { layers) }\end{array}$} & \multicolumn{2}{|c|}{ Load case } & \multirow{2}{*}{$\begin{array}{l}\text { Buckling Load } \\
\text { (N) }\end{array}$} \\
\hline & & $100 \mathrm{kgf}$ on saddle & $\begin{array}{l}100 \mathrm{kgf} \text { at bottom } \\
\text { bracket }\end{array}$ & \\
\hline Top tube & $\sigma_{1}$ & $-15.04(3.2)$ & -176.88 (fail) & \\
\hline \multirow[t]{2}{*}{ (Without aluminium) } & $\sigma_{2}$ & $-9.13(1.3)$ & -85.16 (fail) & 399.0 \\
\hline & $\tau_{12}$ & $7.18(1.3)$ & 107.21(fail) & \\
\hline Top tube & $\sigma_{1}$ & $-1.76(27.7)$ & $-3.02(16.1)$ & \\
\hline \multirow[t]{2}{*}{ (With aluminium) } & $\sigma_{2}$ & $-1.06(11.2)$ & $-1.83(6.5)$ & 1553.8 \\
\hline & $\tau_{12}$ & $0.72(12.4)$ & $1.25(7.2)$ & \\
\hline Bottom tube & $\sigma_{1}$ & $4.20(19.3)$ & $5.50(14.7)$ & \\
\hline \multirow[t]{2}{*}{ (Without aluminium) } & $\sigma_{2}$ & $2.53(4.7)$ & $3.31(3.6)$ & 637.6 \\
\hline & $\tau_{12}$ & $1.86(4.8)$ & $2.43(3.7)$ & \\
\hline Bottom tube & $\sigma_{1}$ & $1.22(66.5)$ & $1.63(49.8)$ & \\
\hline \multirow[t]{2}{*}{ (With aluminium) } & $\sigma_{2}$ & $0.73(16.3)$ & $0.98(12.1)$ & 2832.9 \\
\hline & $\tau_{12}$ & $0.48(18.7)$ & $0.64(14.0)$ & \\
\hline Seat tube & $\sigma_{1}$ & $-2.84(17.1)$ & $3.55(22.8)$ & \\
\hline \multirow[t]{2}{*}{ (Without aluminium) } & $\sigma_{2}$ & $-1.71(7.0)$ & $2.14(5.6)$ & 1017.0 \\
\hline & $\tau_{12}$ & $1.27(7.0)$ & $1.57(5.7)$ & \\
\hline Seat tube & $\sigma_{1}$ & $-0.57(85.4)$ & $0.90(90.1)$ & \\
\hline \multirow[t]{2}{*}{ (With aluminium) } & $\sigma_{2}$ & $-0.35(34.0)$ & $0.55(21.6)$ & 4516.7 \\
\hline & $\tau_{12}$ & $0.23(38.9)$ & $0.36(24.9)$ & \\
\hline
\end{tabular}

It can be seen that the stresses in the composite tubes (with or without aluminium inner layer) are low compared to the maximum strength values, except in the case of the composite top tube without aluminium layer, when $100 \mathrm{kgf}$ are applied to the bottom bracket. The stresses calculated for the aforementioned unique case reach unrealistically high values due to the linear elastic assumption and the composite material would actually fail. There is also the possibility of buckling in compressed loadbearing components. The eigenvalue buckling load analysis was performed using the ABAQUS finite element software and the values of the buckling loads are listed in Table 3. It can be seen that the top tube without aluminium layer has the lowest buckling load. This value is lower than the compressive axial load in the top tube calculated in the case of $100 \mathrm{kgf}$ at the bottom bracket. Therefore, without the aluminium inner layer, the top tube would buckle and fail whereas other tubes would safely withstand the applied loads. By incorporating thin walled aluminium cores, the stresses in all tubes decrease significantly and the buckling loads are considerably increased. However, it can be suggested from the simulation results that the existing bottom tube and seat tube can be replaced with filament wound hemp-epoxy composites without aluminium inner layers while the composite top tube would fail without the aluminium layer.

\section{Discussion and conclusions}

In this work mechanical behaviour of filament wound hemp-epoxy composites made from hemp fibres produced by the Thai Hmong hill tribe was studied. The possibility of utilising the filament wound hemp composite for bicycle frame tubes was investigated. The filament wound hemp-epoxy composite tubes were fabricated using an automated filament winding machine, $\mathrm{X}$-winder. The fibres and matrix used were manufactured and are available in Thailand. For the study, main frame tubes were constructed 
with a winding angle of $45^{\circ}$ resulting in a stacking sequence $\left[ \pm 45^{\circ}\right]_{2}$ over thin-walled tubular aluminium cores. Finite element analyses were performed assuming a linear-elastic behaviour of the materials were carried out to assess the load-bearing capacity of the bicycle frame and main tubes made of filament wound hemp-epoxy composites. Two vertical, in-plane load cases on a bicycle frame were considered. The simulation results reveal that, based on the fabricated main tube dimensions, the composite seat tube and bottom tube can be safely used for the considered load cases. However, the top tube requires the incorporation of an aluminium inner layer with hemp-epoxy composite to be adequately used in a bicycle frame. Nevertheless, if the diameter of the composite top tube is increased, it could possibly be used without the aluminium layer. The results of the study show that hybrid filament wound composite/ aluminium tubular structures can be successfully produced and used adequately for the replacement of existing steel bicycle main frame tubes.

Further studies on different configurations of fibre orientations, variation of tube dimensions, non-linear material modelling and out-of-plane load cases on a bicycle frame should be carried out. The investigation of joining methods on frame joints and experimental tests of the fabricated bicycle frame should also be carried out in the future.

\section{References}

[1] Dhakal, H. N.; Zhang, Z.: The use of hemp fibres as reinforcements in composites. In: Faruk, O.; Sain, M. (eds.). Biofiber Reinforcements in Composite Materials: Woodhead Publishing, 2015, pp. 86-103.

[2] Liu, M.; Thygesen, A.; Summerscales, J.; Meyer, A. S.: Targeted pre-treatment of hemp bast fibres for optimal performance in bio composite materials: A review. Ind. Crops. Prod., 108 (2017), pp. 660-683.

[3] Dhakal, H.N.; Zhang, Z.Y.; Richardson, M.O.: Effect of water absorption on the mechanical properties of hemp fibre reinforced unsaturated polyester composites. Compos. Sci Technol., 67 (2007), pp. 1674-1683.

[4] Pil, L.; Bensadoun, F.; Pariset, J.; Verpoest, I.: "Why are designers fascinated by flax and hemp fibre., Compos. Part A. Appl. S., 83 (2016), pp.193-205.

[5] Shahzad, A.: Hemp fiber and its composites - A review. J. Compos. Mater., 46 (2017) 8, pp. $973-$ 986. 2017

[6] Mobitechure Advanced Design.: Hemp bike. https://www.mobitecture.com/portfolio/hemp-bike. (accessed 20 June 2019).

[7] Charoensilputtakun, T.; Kimkachan, J.; Chanphet, K.: Bicycle frame components from filament wound hemp fibers: Final year student project report, King Mongkut's University of Technology North Bangkok, 2016. (in Thai)

[8] Hyer, M.W.: Stress analysis of fiber reinforced composite materials. McGraw-Hill Inc., 1998.

[9] Madsen, B.; Hoffmeyer, B.; Lilholt, H.: Hemp yarn reinforced composites - II. Tensile properties. Compos. Part A. Appl. S., 38 (2007) 10, pp. 2204-2215.

[10] Cichocki, F.R.; Thomason J.L.: Thermoelastic anisotropy of a natural fiber. Comp. Sci. Tech., 62 (2002) 5, pp. 669-678.

[11] Stowell, E.Z., Liu, T.S.: On the mechanical behaviour of fibre-reinforced crystalline materials. J. Mech. Phys. Solids., 9 (1961), pp. 242-260.

[12] Wȩcławski, B.T.; Fan, M.; Hui, D.: Compressive behaviour of natural fibre composite. Compos Part B-Eng., 67 (2014), pp. 183-191.

[13] Lessard, L.B.; Nemes, J.A.; Lizotte, P.L.: Utilization of FEA in the design of composite bicycle frames. Composites., 26 (1995) 1, pp. 72-74.

[14] Soden, P.D.; Milla, M.A.; Adeyefa, B.A.; Wong,Y.S.: Loads, Stresses, and Deflections in Bicycle Frames. J Strain. Anal. Eng., 21 (1986) 4, pp. 185-195. 